\title{
O TRABALHO E AS ORGANIZAÇÕES: ATUAÇÕES A PARTIR DA PSICOLOGIA
}

\author{
Liliana Andolpho Magalhães Guimarães ${ }^{1}$ \\ Universidade Católica Dom Bosco, Campo Grande-MS, Brasil \\ Eduardo Espíndola Fontoura Junior \\ Universidade Estadual de Mato Grosso do Sul, Dourados-MS, Brasil \\ Helen Paola Vieira Bueno \\ Universidade Federal de Mato Grosso do Sul, Aquidauana-MS, Brasil \\ Kátia Regina Bazzano da Silva Rosi \\ Universidade Federal de Mato Grosso do Sul, Campo Grande-MS, Brasil \\ Márcia Regina Teixeira Minari \\ Universidade Federal de Mato Grosso do Sul, Campo Grande-MS, Brasil \\ Vanusa Meneghel \\ Universidade Católica Dom Bosco, Campo Grande-MS, Brasil
}

A coletânea "O Trabalho e as Organizações: atuações a partir da psicologia" foi organizada por Livia de O. Borges e Luciana Mourão (Borges \& Mourão, 2013). Contou com a participação de dezesseis autores, além de vinte e seis coautores da área da Psicologia do Trabalho e das Organizações - POT - e está dividida em cinco partes, as quais compreendem vinte e três capítulos. Abordando diferentes temas, que mostram toda a extensão da POT na atualidade, a coletânea destina-se principalmente a psicólogos e outros profissionais, estudantes e pesquisadores da área.

A primeira parte apresenta os três eixos da ação do psicólogo nas organizações: compromisso social e ético, a promoção do desempenho individual, grupal e organizacional, e relações de trabalho. O capítulo 1 desta parte foi escrito por Antonio V. B. Bastos, Oswaldo H. Yamamoto e Ana Carolina de A. Rodrigues, que expõem importantes contribuições nas reflexões que o profissional da POT deve ter em sua prática social e ética nas organizações, haja vista que suas ações têm repercussões sociais significativas. O capítulo 2 foi escrito por Pedro
F. Bendassolli e Sigmar Malvezzi, que apresentam modelos teóricos que explicam, predizem e sugerem intervenções sobre 0 desempenho nos ambientes organizacionais. No capítulo terceiro, Livia de O. Borges e José Luis Álvaro discutem subsídios teóricos sobre as relações de trabalho, no cenário de negociações sindicais/coletivas em relação à mediação do Estado.

A segunda parte, que compreende os capítulos 4, 5 e 6, versa sobre temas que desafiam o psicólogo a fazer ligações entre o fenômeno psicológico, a estratégia organizacional e a sociedade. No capítulo 4, Janice J. de Souza e Adriano de L. A. Peixoto descrevem as formas de estruturação, organização e funcionamento das instituições, abordando a gestão da produção, a organização do trabalho, as relações de emprego, modelos de alto desempenho e o contexto brasileiro. $O$ capítulo 5, escrito por Elisabeth Loiola, Antonio V. B. Bastos, Magno O. Macambira, Elaine R. Neiva e Jessé A. P. Machado, expõe um histórico sobre as redes sociais em contextos organizacionais, discorrendo sobre seus conceitos, seus elementos constituintes (suas

1 Endereço para correspondência: Programa de Pós-Graduação Mestrado e Doutorado em Psicologia. Av. Tamandaré, 6000. Jardim Seminário, CEP 79.1179-00, Campo Grande-MS, Brasil. E-mail: Iguimaraes@mpc.com.br. 
estratégias de coleta de dados, níveis de análise, propriedades e indicadores, análise de posição e papéis) e sua aplicabilidade. No capítulo 6, os autores Kátia B. Macêdo, Alberto de Oliveira, Roberto Heloani e Rosângela Cassiolato apresentam o embasamento histórico-político da gestão ambiental nas organizações e mostram que estas tiveram que aprender novas possibilidades neste sistema e adequar-se às exigências internacionais, surgindo assim um novo perfil de psicólogo para atender às demandas atuais do mercado de trabalho.

A terceira parte, que compreende os capítulos 7. 8, 9, 10 e 11, trata das ações profissionais que devem ser desenvolvidas nos níveis organizacional, grupal e interpessoal, temática que perpassa transversalmente as demais que compõem esta coletânea. No capítulo 7, Luciana Mourão, Jairo Eduardo Borges-Andrade e Sonia Maria G. Gondim discorrem sobre a crescente necessidade de se criarem ferramentas metodológicas para avaliar a eficiência, a eficácia e a efetividade de planos, programas e projetos no âmbito das ações sociais e organizacionais. No capítulo 8, Narbal Silva, José Carlos Zanelli e Suzana da R. Tolfo apresentam a complexidade de realizar um diagnóstico de como é construída a cultura organizacional e sua composição, por meio dos três níveis de análise. Kátia Puente-Palacios e Maria do Carmo F. Martins permitem que o leitor compreenda, no capítulo 9, o que é clima organizacional, suas características, dimensões, evolução histórica, níveis de constructo, mensuração e análise e seu papel no cenário organizacional. O capítulo 10, escrito por Antonio V. B. Bastos, Ana Carolina de A. Rodrigues, Daniela C. B. Moscon, Eliana E. da Costa e Silva e Ana Paula M. Pinho, tem como principal objetivo discutir o comprometimento no trabalho, sua importância como vínculo e base para a vida das pessoas, grupos e organizações. No capítulo 11, Kátia Puente-Palacios e Vicente GonzálezRomá analisam as definições e características das equipes de trabalho nas organizações, com o objetivo de adotar estratégias de gestão que favoreçam um melhor aproveitamento do desempenho das organizações, em seus diferentes setores.

A quarta parte do livro, que compreende os capítulos de 12 a 18, embasa a atuação prática do psicólogo e/ou de profissionais que trabalham no planejamento de metodologias de trabalho de gestão de pessoas, desde a inserção do trabalhador na organização, o processo de educação até o seu acompanhamento. No capítulo 12, Sonia Maria G. Gondim, Janice J. de Souza e Adriano de L. A. Peixoto relatam modelos, sistemas e desafios que visam munir o psicólogo de conhecimentos e ferramentas acerca do processo de gestão de pessoas, para uma atuação reflexiva com vista à melhoria da qualidade de vida do trabalhador, a seu bemestar e ao da organização. O capítulo 13, escrito por Sonia Maria G. Gondim e Fabiana Queiroga, traz informações teóricas e técnicas e os desafios da área de recrutamento e seleção de pessoas, abordando o processo de seleção baseado em resultados de pesquisas nacionais e internacionais que investigam o valor preditivo dos instrumentos psicológicos da POT, o que favorece a tomada de decisões relativas ao processo seletivo. Livia de O. Borges e Virgínia D. Carvalho, no capítulo 14, expõem um tema emergente na área do Trabalho e das Organizações, que é o processo de tutoramento e/ou mentoring de novos empregados, discutindo a aplicação, o planejamento, a implantação e a fixação de critérios para realizar o acompanhamento e avaliação de programas de tutoramento organizacional. O capítulo 15, escrito por Mauro de O. Magalhães e Pedro F. Bendassolli, discorre sobre o referencial teórico que subsidia o entendimento do processo de desenvolvimento de carreira nas organizações, enfocando a importância do contrato psicológico entre indivíduo e empresa e as corresponsabilidades dos diversos setores envolvidos neste processo. No capítulo 16, Jairo Eduardo Borges-Andrade, Thaís Zerbini, Gardênia da S. Abbad e Luciana Mourão tratam de um modelo de gestão de Treinamento, Desenvolvimento e Educação - TD\&E, apresentando as bases conceituais, os processos, os procedimentos, os possíveis resultados de eventos, os ambientes de ação nos níveis micro e macro da organização que marcam as práticas de TD\&E. No capítulo 17, Gardênia da S. Abbad, Elizabeth Loiola, Thaís Zerbini e Jairo Eduardo Borges-Andrade apresentam os conceitos, tipologia, processos, resultados e estratégias de aprendizagem individual e organizacional, haja vista que a qualificação dos quadros de pessoal das organizações é uma necessidade fundamental que se faz presente. No capítulo 18, Adriano de L. A. Peixoto e António Caetano debatem conceitos acerca de princípios e regras sobre a 
Avaliação de Desempenho, apresentando sua evolução, os componentes avaliados (pessoa, comportamentos, resultados e contexto), os tipos, as etapas do processo e as perspectivas para esta área.

A quinta e última parte desta coletânea, constituída dos capítulos de 19 a 23, tem como foco o indivíduo, e nela se discute a promoção do bem-estar dos trabalhadores. No capítulo 19, Mário César Ferreira, Cleverson P. de Almeida e Magali C. Guimarães oferecem uma visão geral sobre a Ergonomia da Atividade, abordando seus fundamentos teóricos metodológicos e seus limites, enfocando os problemas da pessoa na organização. O capítulo 20 , elaborado por Livia de O. Borges, Liliana A. M. Guimarães e Sandra S. da Silva, apresenta e discute o campo da Saúde Psíquica e Trabalho, na perspectiva do diagnóstico, prevenção, assistência e reabilitação psíquica nas organizações. As autoras dividem em três sua forma de abordagem: as formas individualista, psicodinâmica do trabalho e psicossociológica, descrevendo suas peculiaridades e as ações do psicólogo em cada uma delas. O capítulo 21, escrito por Mirlene Maria M. Siqueira e Maria do Carmo F. Martins, aborda questões da promoção da saúde e bem-estar nas organizações à luz da Psicologia Positiva, trazendo cinco temas: saúde social, saúde positiva, bem-estar, comportamento organizacional e saúde nas organizações. O capítulo 22, escrito por José Carlos Zanelli, Narbal Silva e Núria Tordera, relata o planejamento da aposentadoria como uma práxis cultural das organizações brasileiras que busca desenvolver ações para um envelhecimento saudável e com qualidade de vida, pois a aposentadoria é uma etapa do ciclo vital e da carreira das pessoas. O capítulo 23, escrito por Vanessa A. de Barros e Dominique Lhuilier, contempla a análise do trabalho de presos como uma possibilidade de ampliação do campo de pesquisa e da ação da POT, demonstrando que existe uma hierarquia de profissões que são mais ou menos valorizadas socialmente. Este capítulo expõe o trabalho no interior das prisões, apresentando dados nacionais sobre a população encarcerada e o trabalho, a visão que o poder público tem sobre o trabalho dos presidiários e as funções deste no sistema prisional.

Esta coletânea contribui para o conhecimento sistematizado de como vem se desenvolvendo a POT, que é marcada pela crescente complexidade nos domínios acadêmico, científico e profissional, ampliando as discussões para além da organização, enfocando o trabalho, a carreira e também a inclusão social. Recomenda-se sua leitura para estimular a reflexão e as práticas baseadas na eficiência, ética e disseminação emergente da Psicologia do Trabalho e das Organizações na contemporaneidade.

\section{REFERÊNCIAS}

Borges, L. O. \& Mourão, L. (Orgs.). (2013). O Trabalho e as Organizações: atuações a partir da Psicologia. São Paulo: Artmed.

Liliana Andolpho Magalhães Guimarães: mestre em Psicologia da Saúde, doutora em Saúde Mental, pós-doutora em Medicina do Estresse; professora titular do Mestrado e Doutorado em Psicologia da Universidade Católica Dom Bosco, Brasil.

Eduardo Espíndola Fontoura Junior: mestre em Ciências da Saúde pela Universidade de Brasília, doutorando em Psicologia da Saúde pela Universidade Católica Dom Bosco; professor da Universidade Estadual de Mato Grosso do Sul, campus Dourados-MS, Brasil.

Helen Paola Vieira Bueno: mestre em Psicologia pela Universidade Católica Dom Bosco, doutoranda em Psicologia da Saúde na mesma universidade; professora e coordenadora do curso de Educação da Universidade Federal de Mato Grosso do Sul - Campus Aquidauana-MS, Brasil.

Kátia Regina Bazzano da Silva Rosi: mestre em Psicologia pela Universidade Católica Dom Bosco, doutoranda em Psicologia da Saúde na mesma universidade; professora da Universidade Federal de Mato Grosso do Sul, Brasil.

Márcia Regina Teixeira Minari: mestre em Psicologia pela Universidade Católica Dom Bosco, doutoranda em Psicologia da Saúde na mesma universidade; psicóloga da Saúde Ocupacional da Universidade Federal de Mato Grosso do Sul, Brasil.

Vanusa Meneghel: mestre em Psicologia pela Universidade Católica Dom Bosco, Brasil. 